\title{
Evaluation of Milling Machine Properties Based on Shape Errors
}

\author{
Paweł Piórkowski ${ }^{1 *}$, Wacław Skoczyński ${ }^{1}$ \\ 1 Faculty of Mechanical Engineering, Wrocław University of Science and Technology, Wybrzeże Wyspiańskiego \\ 27, 50-370 Wrocław, Poland \\ * Corresponding author's email: pawel.piorkowski@pwr.edu.pl
}

\begin{abstract}
A procedure for assessing the properties of a milling machine based on machining tests was presented, with particular emphasis on shape errors and properties of the workpiece surface layer. The selection of an appropriate test-piece and cutting parameters for such a test was discussed. A mathematical formula was also presented, which allows to associate the accuracy of the test-piece with that of the milling machine. The proposed test procedure was verified by evaluating the DMC $1035 \mathrm{~V}$ Ecoline vertical machining centre.
\end{abstract}

Keywords: milling, milling machine properties, property evaluation, shape errors, test-pieces.

\section{INTRODUCTION}

In the last few decades, the requirements for machining accuracy in technologies such as turning, milling or drilling have increased significantly. In case of many machining methods, the total accuracy of machining increases by an order of magnitude even within 20 years [1]. The spectrum of workpieces that can be made by machining is also growing, as the development and technological capabilities of modern machine tools allow to produce workpieces that were previously impossible to manufacture [2].

Due to the fact that there is a clear trend towards increasing the accuracy of machine tools [3], it is necessary to identify and evaluate various types of errors, which are the result of increasingly complex and advanced construction of modern cutting machines [4].

Since there are so many different errors that can be determined in a cutting machine tool, it is reasonable to ask yourself which errors are the most important and what interests the user of such a machine in terms of accuracy. It seems that the most important accuracy-related features that interest the user of the machine tool are those related to the operating properties and the resulting machining accuracy. As there is a strong correlation between the quality parameters of products made by machining methods and the quality parameters of machines that have performed this machining [5], it can be assumed that the most comprehensive way of evaluating a cutting machine tool will be to develop a procedure that takes into account the accuracy of the workmanship of the workpiece.

Such a procedure, based on the possibility of linking the evaluation of milling machine properties with ISO accuracy classes and the probability distribution of machining operations in the working space of the milling machine, depending on the machining tasks set by the user, is presented in this article.

\section{METHOD OF ASSESSING MILLING MACHINE PROPERTIES}

The general method of assessing the properties of numerically controlled milling machines will be adapted on the basis of machining tests [6], while the determination of the probability 
distribution of machining operations in the machine's working space will be carried out on the basis of a special application [7] and machining programs designed for the DMC $1035 \mathrm{~V}$ Ecoline vertical machining centre in the selected plant of the machine industry. The result of the procedure of assessing the properties of a milling machine, in accordance with the proposed method, will be an indicator which will inform about the class of accuracy with which the milling machine is capable of machining.

The table of numerical values of normal IT tolerances [8], from which two groups of nominal dimensions $\mathrm{z}$ : from 0 to $500 \mathrm{~mm}$ and from 500 to $3150 \mathrm{~mm}$ were separated, was used to determine the $W$ evaluation indicators. This division was used because other ways of calculating normal tolerance units are used for these dimensional groups. For the various nominal dimensions $z$, graphs of the dependence of the proposed $W$ indicator (with numerical values corresponding to ISO accuracy classes) on the normalised normal IT tolerances have been drawn up. If it is assumed that the total deviation of the nominal dimension $\Delta z$ should not be greater than the tolerance of the IT dimension $(\Delta z \leq \mathrm{IT})$, then the evaluation index $W$ determined for a specific dimension $z$, takes the form [6]:

$$
\begin{gathered}
W=5 \log (2.5 \cdot \Delta z)-1.72 \log (z)+2.68 \\
\text { dla } 0 \leq z \leq 500 \\
W=5 \log (2.5 \cdot \Delta z)-3.44 \log (z)+7.33 \\
\text { dla } 500 \leq z \leq 3150
\end{gathered}
$$

where: $W$ - evaluation index taking into account the properties of the machine tool on the basis of total dimensional deviation, $\Delta z$ total dimensional deviation $[\mu \mathrm{m}], z$ - actual dimension obtained during machining of the test piece $[\mathrm{mm}]$.

The total dimensional deviation consists of deviations caused by the static deformation of the machine tool, caused by geometrical errors and machine vibrations and related to surface roughness. The subject of this work is evaluation of a machine tool on the basis of shape errors and properties of the surface layer of the workpiece. Therefore, a total dimensional deviation, which is taken naturally as the sum of the partial deviations. In order to apply the proposed index to equivalent partial evaluations that are used for a full machine tool evaluation, equivalent total dimensional deviations may be introduced, taken as follows:

$$
\Delta z=2.5 \Delta z_{1}
$$

$$
\Delta z=2.86 \Delta z_{2}
$$

where: $\Delta z_{1}$ - dimensional deviation resulting from shape errors caused by geometrical errors and vibrations of the machine tool $[\mu \mathrm{m}], \Delta z_{2}$ - dimensional deviation resulting from the roughness deviation $[\mu \mathrm{m}]$.

The numbers adopted in the denominators of expressions (3) and (4) result from the fact that, based on statistical studies $[9,10]$, the shares of acceptable roughness deviations were assumed to be - 35\%, and of acceptable shape deviations - $40 \%$ of dimensional tolerance. The total permissible deviation must not exceed the dimensional tolerance. Dividing each of the considered partial deviations by its share in the dimension tolerance makes it possible to relate them equally to the equivalent total dimension deviation and the indicator related to the accuracy class. It therefore allows each of these partial deviations to be assessed independently of the others. By substituting the equivalent deviation in formula (1) or (2), the evaluation index $W_{1}$ can be determined, which takes into account, on the basis of shape errors, the dynamic properties of the machine tool and the resulting geometric accuracy and the evaluation index $W_{2}$, taking into account the quality of the surface layer of the test-piece based on surface roughness measurements.

Dependencies (1) or (2) were used to determine the local evaluation indicators in the work subspaces of the milling machine where machining was most likely to occur. In order to average the results across the entire workspace a global evaluation index $W_{g}$ was introduced, which was a weighted average of all the $n$ subspaces under consideration. The weights are taken as the probabilities of the machining in a given subspace. The global evaluation index $W_{g}$ has taken the form of the following relationship:

$$
W_{g}=\sum_{i=1}^{n} w_{i} W_{i}
$$

where: $W_{i}$ - local evaluation index in the $i$-th subspace, $w_{i}$ - normalized weight factor in the $i$-th working space, $n$ - the number of working areas with the highest probability $(>5 \%)$ of machining.

\section{SELECTION OF THE TEST-PIECE}

The selection of the test-piece used in the procedure for assessing the properties of a numerically controlled milling machine must primarily take into account the load distribution in 


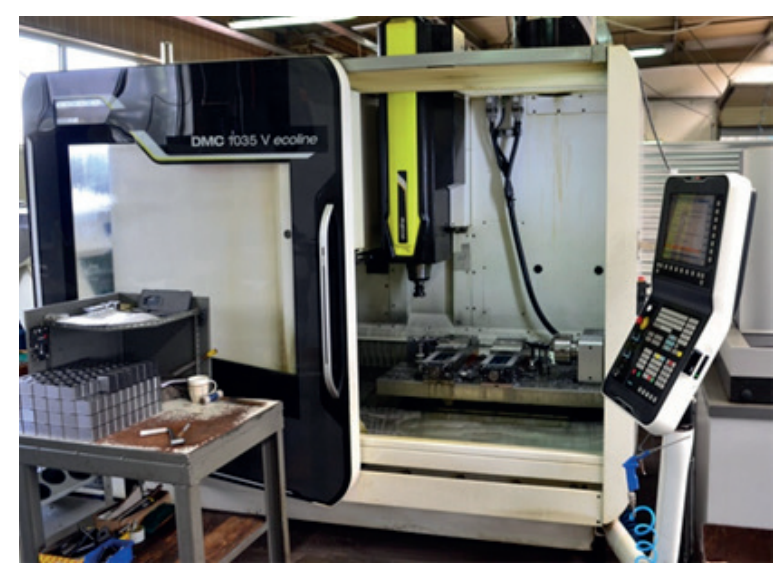

Fig. 1. DMC 1035 V Ecoline vertical machining center

the machine's working space. The test-piece shall be of such shape that it can be machined in one clamping in all representative subspaces of the milling machine workspace. After analyzing the machining tasks to be performed on the DMC 1035V Ecoline vertical machining centre (Figure 1) at the selected user, the probabilities of the cutting tool position in the machine tool's working space, determined with the appropriate program [11], have been obtained as shown in Table 1 . The entire working space of the milling machine was divided into cuboidal subspaces, whereas, towards the direction of the $\mathrm{x}$ and $\mathrm{y}$ axis, an even division was applied, respectively, into five and four identical ranges, and in the direction of the $\mathrm{z}$ axis individual ranges overlapped with the ranges of nominal dimensions (14 ranges).

Based on the results presented in Table 1, it can be observed that machining on the machining centre under analysis is mostly carried out in the height range of $18-50 \mathrm{~mm}$, in eight concentrated subspaces (Figure 2), out of 280 subspaces, into which the whole working space is divided. This area accounts for $85.3 \%$ of all machining operations. This fact made it much easier to choose the right test-piece.

Test-pieces must also fulfil other conditions. The already withdrawn standard for test-pieces used in the testing of metalworking machines [12] set the following requirements for test-pieces:

- They should correspond to the main purpose of the machine,

- They should be determined according to the size of the machine tool,

- The fastening and construction shall provide adequate rigidity.

In addition, the accuracy of the test-piece should be checked outside the machine tool. Another standard [13] additionally indicates that the shape of the workpiece to be used as a testpiece can be replaced by a simpler one with full sides. The recommendations therefore indicate that the shape of the workpiece can be selected over a wide range and that it is more important to adapt the size of the workpiece to the machine tool and ensure adequate rigidity. Currently, there are no strict standardization recommendations concerning the shape of the test item used

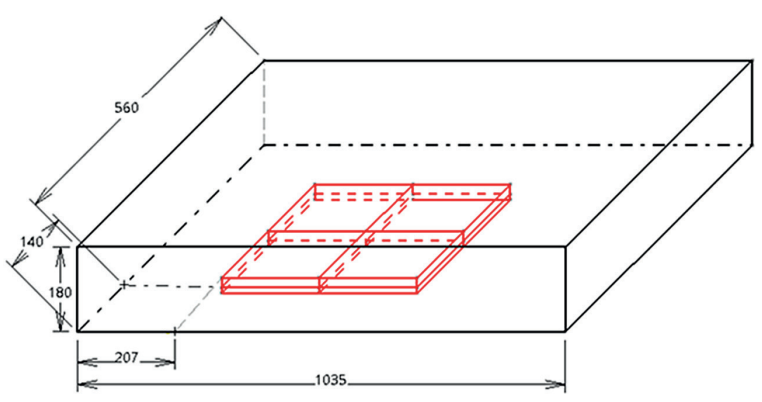

Fig. 2. Diagram of distribution of selected subspaces of the milling machine's working spaces, in which machining operations are most likely to occur

Table 1. Subspaces where machining operations are most likely to occur

\begin{tabular}{|c|c|c|c|c|}
\hline $\begin{array}{c}\text { Range of nominal } \\
\text { dimensions on the } \\
\mathbf{z} \text { axis }[\mathrm{mm}]\end{array}$ & $\begin{array}{c}\text { Dimensional range } \\
\text { on the } \mathbf{x} \text { axis }[\mathrm{mm}]\end{array}$ & $\begin{array}{c}\text { Dimensional range } \\
\text { on the } \mathbf{y} \text { axis [mm] }\end{array}$ & $\begin{array}{c}\text { Probability of } \\
\text { frequency of events [\%] }\end{array}$ & $\begin{array}{c}\text { Subspace } \\
\text { designation }\end{array}$ \\
\hline $30-50$ & $207-414$ & $140-280$ & 21.51 & $\mathrm{~A}$ \\
\hline $30-50$ & $207-414$ & $280-420$ & 11.34 & $\mathrm{~B}$ \\
\hline $30-50$ & $414-621$ & $140-280$ & 14.19 & $\mathrm{C}$ \\
\hline $30-50$ & $414-621$ & $280-420$ & 10.06 & $\mathrm{E}$ \\
\hline $18-30$ & $207-414$ & $140-280$ & 10.34 & $\mathrm{~F}$ \\
\hline $18-30$ & $207-414$ & $280-420$ & 5.83 & $\mathrm{G}$ \\
\hline $18-30$ & $414-621$ & $140-280$ & 6.91 & $\mathrm{H}$ \\
\hline $18-30$ & $414-621$ & $280-420$ & 5.12 & \\
\hline
\end{tabular}


in assessing the properties of machining centres. On the other hand, work is in progress to standardize the tests of 5-axis machine tools [14], as well as to establish and verify the appropriate shape of the test-pieces [15]. These proposals (Figure 3), due to their shape, cannot be used for testing a three-axis milling machine.

In addition to the geometry recommendations, there are also recommendations concerning the material of which the test-piece is made. The three most common materials in the standards are aluminum, steel and cast iron. Due to the dominant role of steel in milling operations, as well as the fact that the selected machine tool performs machining operations only on workpieces made of structural steel, this material will also be used for the procedure of assessing the properties of the milling machine. In order to allow the test-piece machining process to be carried out as quickly as possible, so as to minimize set-up time, it was decided that the shape of the piece would allow

a)
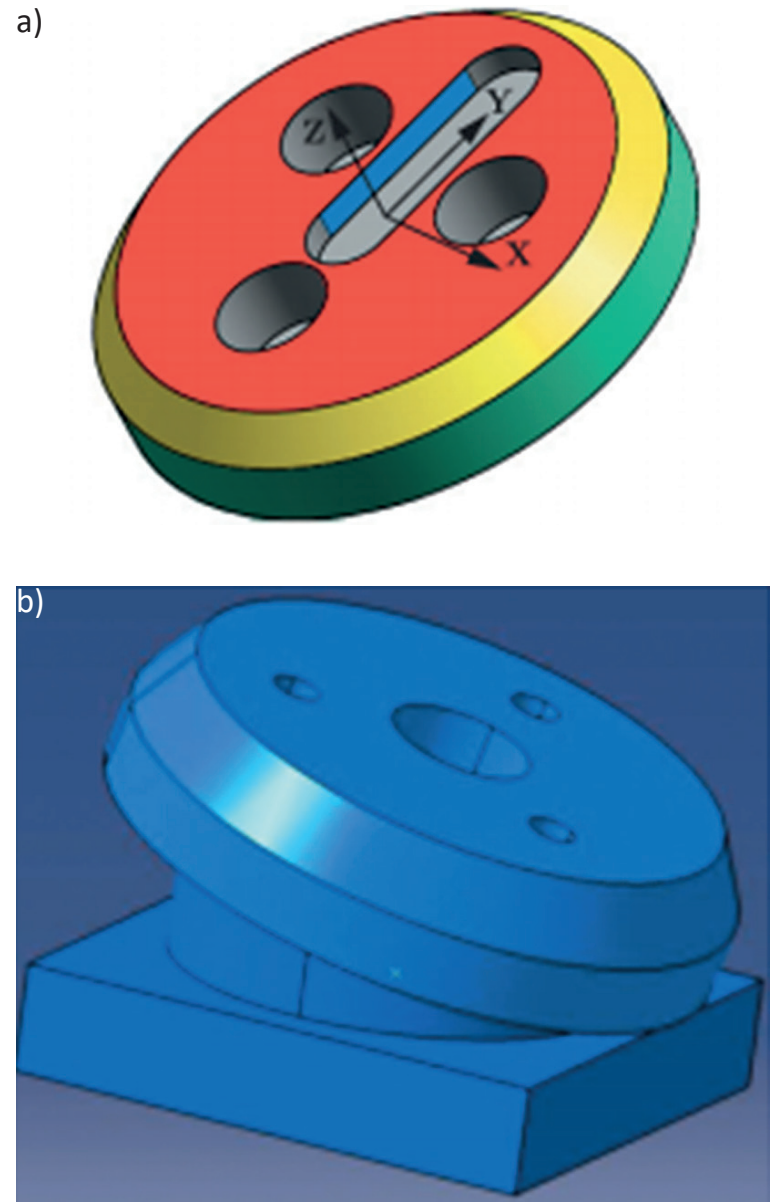

Fig. 3. Proposed test-pieces for testing the accuracy of 5-axis machining centres (a) the proposal of Bossoni [16], (b) the proposal of Wolny [17] machining to be carried out in all subspaces of the machine's workspace in one clamping. After taking into account the above recommendations and the data on load distribution in the machine's working space (Figure 2, Table 1) a design of the test-piece was created (Figure 4). The proposed test piece allows machining to be carried out without the need to retool the machine. The item will be made of $\mathrm{C} 45+\mathrm{N}$ steel.

\section{TOOL SELECTION FOR MACHINING TESTS AND CUTTING PARAMETERS}

The dimension from which the evaluation indicators will be determined will be the dimension along the $\mathrm{z}$ axis, so the tool with which the machining will be carried out should be a shell mill. Such a tool is also recommended in the above mentioned standards. It is much more difficult to choose the right tool diameter, since the standardization recommendations propose milling cutters with diameters of 30,50 and even $100 \mathrm{~mm}$. In the literature, smaller cutters are often used [15], even with a diameter of $20 \mathrm{~mm}$.

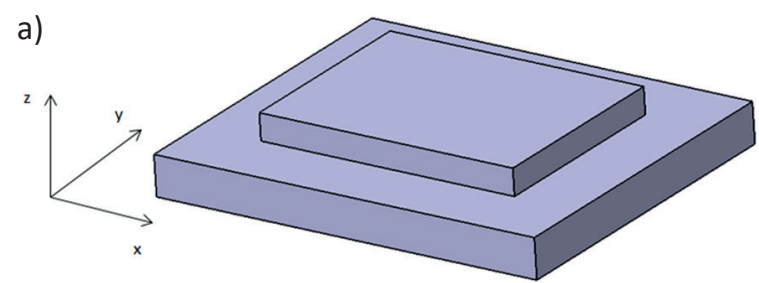

b)

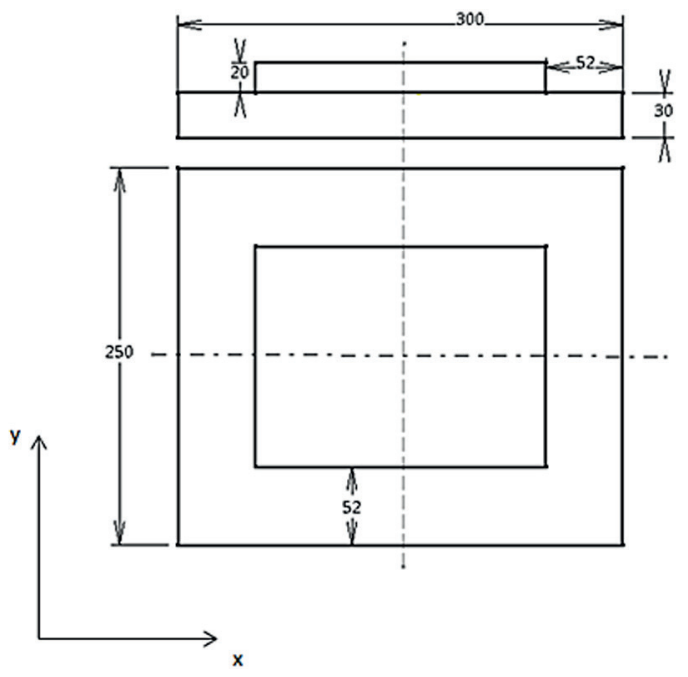

Fig. 4. Proposed test-piece for evaluation of properties of a numerically controlled milling machine taking into account the load distribution in the machine's working space (a) model, (b) dimensions 


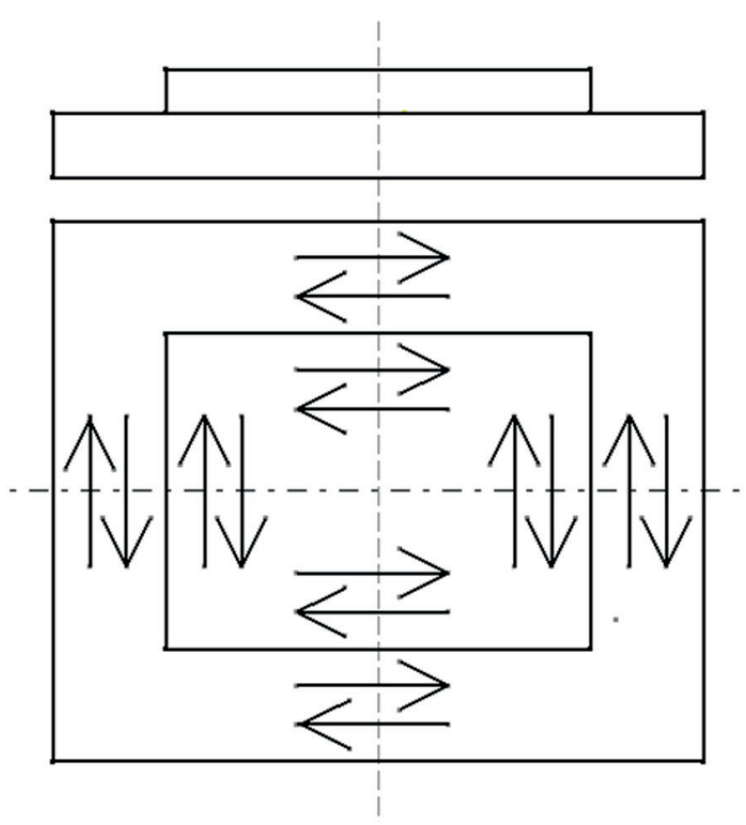

Fig. 5. Proposed toolpaths for evaluating the properties of a numerically controlled milling machine

Taking into account the proposed test-piece, it is necessary to use a small diameter tool as the subspaces along the y axis have a dimension of $140 \mathrm{~mm}$ and at least two runs within this dimension are necessary. Taking into account the above, as well as information on the typical diameters most commonly used in tool milling operations, it has been established that the diameter of the used shell mill will be $25 \mathrm{~mm}$. This tool will perform the machining by means of parallel and counter-rotating milling. The proposed toolpaths are shown in Figure 5.

The evaluation of the properties of a numerically controlled milling machine should take place under the conditions of the finishing machining, and it is therefore necessary to select appropriate cutting parameters for this type of machining. The already withdrawn standard [12] for acceptance testing of milling machines indicates that finishing should be carried out at a depth of cut of $0.2,0.5$ or $1.0 \mathrm{~mm}$ and a feed per tooth of 0.05 to $0.1 \mathrm{~mm} /$ tooth. It has been established that the parameters proposed by the standard will be selected for testing, so the depth of cut in the test will be $0.2 \mathrm{~mm}$ and the feed per tooth will be $0.1 \mathrm{~mm} /$ tooth. The same standard also recommends a cutting width of $80 \%$ of the mill diameter. However, this is due, among other things, to the dimensions of the test-piece used in this standard. Taking into account the industry's aspirations for continuous productivity growth and the frequent use of full-width machining during finishing, the cutting width will be $100 \%$ of the tool diameter, i.e. $25 \mathrm{~mm}$.

There are many types of cutting inserts that can be used in the developed evaluation of the properties of milling machines, but the differences between them are not significant from the point of view of the evaluation method, and therefore the inserts that are used on the tested machine tool during machining will be selected. These are Sandvik Coromant inserts with the designation R390-1704 16M-PM 4240. The cutting speed is selected based on the values recommended by the manufacturer for finishing and will be $250 \mathrm{~m} / \mathrm{min}$. As a result, the spindle speed will be $3185 \mathrm{rpm}$. In order to determine surface shape errors and errors resulting from the properties of the surface layer, 3 cutting tests were performed each using the toolpaths shown in Figure 5.

\section{SHAPE ERROR EVALUATION}

Errors in the shape of the cut surface are mainly due to machine vibration and geometric errors. The tested parameter was the maximum waviness height $W_{t}$. The measurements were taken with the Carl Zeiss Contura G2 measuring machine (Figure 6).

For each of the subspace of the machine tool working space, 3 measurements of surface waviness were carried out for each of the 4 cutting

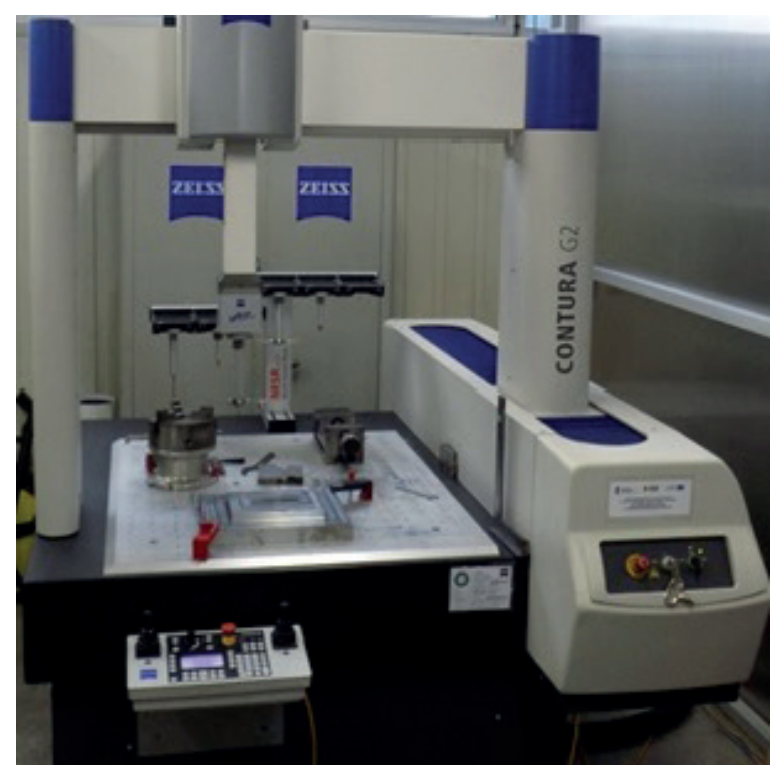

Fig. 6. The measurement of waviness height on Carl Zeiss Contura G2 measuring machine 
directions, for each of the 3 cutting tests. The mean values of the 36 measurements taken together with the standard deviations for each of the $8 \mathrm{~A}-\mathrm{H}$ subspaces are shown in the table (Table 2 ). It was assumed that the shape error $\Delta z_{1}$ would correspond to twice the value of the waviness parameter $W_{t}$, because it was assumed that the base surface of the test item was machined with the same accuracy, corresponding to finishing. For the shape errors determined in this way, the local $W_{1}$ evaluation indicators were calculated in each of the analyzed subspaces.

The local indicators for the evaluation of the error of the shape of the area $W_{1}$ range from 5.89 to 6.47 , which means that the difference between the indicators in individual subspaces is 0.58 maximum. For the results obtained, the global index of shape error evaluation $W_{1 g}$ was determined as a weighted average of the calculated local evaluation indexes $W_{1}$, as per relation (5). It was 6.21 . This means that, taking into account only surface shape errors, the test machine is capable of finishing parts in ISO precision class 7 , and in two subspaces of the machine tool working space ( $\mathrm{C}$ and $\mathrm{F}$ ) the result obtained indicates the possibility of performing on this machine tool objects with shape errors in ISO precision class 6 . As with roughness measurement, tool change or other cutting parameters could change to a small extent the surface shape error evaluation index and the machine, according to the evaluation method carried out, would be able to regularly obtain surface shape errors of the workpiece in ISO accuracy class 6 .

\section{ROUGHNESS ERROR EVALUATION}

In order to determine the roughness errors, the same 3 cutting tests were used, made according to the adopted machining strategy, without the use of a cooling and lubricating fluid. Since the roughness parameter is significantly influenced by the wear condition of the cutting tool, the cutting tests were performed each time with new inserts. The tested parameter was the maximum roughness height $R_{t}$. Measurements were taken using the Mitutoyo SJ-201 roughness

Table 2. Local indicators for shape error evaluation $W_{1}$ specified for the vertical milling centre under test

\begin{tabular}{|c|c|c|c|c|c|c|}
\hline $\begin{array}{l}\text { Designation of } \\
\text { the subspace of } \\
\text { the working space } \\
\text { of the machine tool }\end{array}$ & $\begin{array}{l}\text { Normalized } \\
\text { weighting } \\
\text { factors "w" }\end{array}$ & $\begin{array}{c}\text { Waviness } \\
\text { height } W_{t} \\
{[\mu \mathrm{m}]}\end{array}$ & $\begin{array}{c}\text { Standard } \\
\text { deviation } \\
s[\mu \mathrm{m}]\end{array}$ & $\begin{array}{c}\text { Dimension } \\
\text { deviation } \\
\text { due to shape } \\
\text { errors } \Delta z_{1}[\mu \mathrm{m}]\end{array}$ & $\begin{array}{l}\text { Local indicators } \\
\text { for evaluation of } \\
\text { surface shape } \\
\text { errors } W_{1}\end{array}$ & $\begin{array}{c}\text { Actual } \\
\text { dimension } \\
\text { after machining } \\
{[\mathrm{mm}]}\end{array}$ \\
\hline A & 0.12 & 4.16 & 0.13 & 8.32 & 6.35 & 50 \\
\hline$B$ & 0.17 & 4.40 & 0.08 & 8.80 & 6.47 & 50 \\
\hline$C$ & 0.13 & 3.37 & 0.14 & 6.74 & 5.89 & 50 \\
\hline$D$ & 0.25 & 3.88 & 0.22 & 7.76 & 6.20 & 50 \\
\hline$E$ & 0.06 & 2.99 & 0.18 & 5.97 & 6.01 & 30 \\
\hline $\mathrm{F}$ & 0.08 & 2.97 & 0.20 & 5.93 & 5.99 & 30 \\
\hline $\mathrm{G}$ & 0.07 & 3.65 & 0.26 & 7.29 & 6.44 & 30 \\
\hline $\mathrm{H}$ & 0.12 & 3.03 & 0.17 & 6.05 & 6.04 & 30 \\
\hline
\end{tabular}

Table 3. Local indicators of the $W_{2}$ surface roughness evaluation defined for the vertical milling centre under test

\begin{tabular}{|c|c|c|c|c|c|c|}
\hline $\begin{array}{c}\text { Subspace of } \\
\text { of the workspace } \\
\text { of the machine tool }\end{array}$ & $\begin{array}{c}\text { Normalized } \\
\text { weighting } \\
\text { factors "w" }\end{array}$ & $\begin{array}{c}\text { Roughness } \\
\text { height } \boldsymbol{R}_{\boldsymbol{t}} \\
{[\boldsymbol{\mu \mathrm { m } ]}}\end{array}$ & $\begin{array}{c}\text { Standard } \\
\text { deviation } \\
\mathbf{s}[\boldsymbol{\mu m}]\end{array}$ & $\begin{array}{c}\text { Dimensional } \\
\text { deviation resulting } \\
\text { from roughness } \\
\text { deviation } \boldsymbol{\Delta}_{\mathbf{2}}[\boldsymbol{\mu} \boldsymbol{m}]\end{array}$ & $\begin{array}{c}\text { Local roughness } \\
\text { evaluation } \\
\text { indicators } \mathbf{W}_{\mathbf{2}}\end{array}$ & $\begin{array}{c}\text { Actual } \\
\text { dimension } \\
\text { after machining } \\
{[\mathbf{m m}]}\end{array}$ \\
\hline A & 0.12 & 3.57 & 0.23 & 7.13 & 6.30 & 50 \\
\hline B & 0.17 & 4.25 & 0.41 & 8.49 & 6.68 & 50 \\
\hline C & 0.13 & 3.31 & 0.17 & 6.62 & 6.14 & 50 \\
\hline D & 0.25 & 3.53 & 0.18 & 7.06 & 6.28 & 50 \\
\hline F & 0.06 & 2.67 & 0.08 & 5.33 & 6.05 & 30 \\
\hline G & 0.08 & 2.06 & 0.23 & 5.31 & 6.05 & 30 \\
\hline H & 0.07 & 3.77 & 0.16 & 7.54 & 6.81 & 30 \\
\hline
\end{tabular}


meter with $2.5 \mu \mathrm{m}$ radius of rounding the measuring tip. The length of the sampling during measuring roughness was $5.5 \mathrm{~mm}$.

For each of the 8 subspaces of the machine tool working space, 3 measurements of roughness were carried out for each of the 4 cutting directions, for each of the 3 cutting tests. The mean values of 36 measurements of these subspaces (A-H) are shown in the table (Table 3).

As in the case of the evaluation of shape errors, it was assumed that the roughness error $\Delta z_{2}$ would correspond to twice the value of the roughness parameter $R_{t}$. It results from the assumption that the same roughness was obtained for the base surface of the test-piece. The local indicators for the evaluation of the roughness of the area $W_{2}$ range from 6.05 to 6.81 , which means that the difference between the indicators in individual subspaces is 0.76 maximum. The global roughness index $W_{2 g}$ was 6.27. This means that, taking into account only the surface roughness, the test machine is able to perform finishing work on parts in ISO precision class 7. It is possible that using other cutting parameters and tools, the index value corresponding to ISO accuracy class 6 could be obtained.

\section{CONCLUSIONS}

The indicators presented allow to determine with numerical values related to ISO accuracy classes, the accuracy of the numerically controlled milling machine in terms of shape errors and properties of the surface layer of the test-piece. The machining tests allow you to assign a dimensionless numerical value to a given milling machine, with which you can compare different machine tools.

The research carried out shows that in different parts of the machine's working space, using the same tool and the same cutting parameters, different machining accuracies are obtained. The performance of machining tests, taking into account the distribution of probabilities of machining operations in the working space of the milling machine for user-defined machining operations, allows for an evaluation close to the actual accuracy of the machine achieved in machining processes. The evaluation methods described in the literature, based on the fulfilment of certain limit values for certain errors or based on tests under certain limit conditions, are of less practical significance compared to the presented method of evaluation of properties.
The machine, on which the verification of the property evaluation method has been carried out, is used for milling flat objects in ISO accuracy class 7 . The results obtained using the presented method of property evaluation are consistent with the accuracy obtained under industrial conditions. This allows us to believe that the results in the form of the designated property evaluation indexes are correct and it is possible to carry out the procedure of evaluating the properties of a numerically controlled milling machine, taking into account the technological tasks set for the milling machine, using the proposed machining tests.

\section{REFERENCES}

1. Taniguchi N. Nanotechnology: integrated processing systems for ultra-precision and ultra-fine products. New York: Oxford University Press, 1996.

2. Honczarenko J. Current machine tools open up new prospects for production engineering projects. Mechanik, 2012, 84(10), 761-767.

3. Portman V.T. Deterministic metrology of parallel kinematic machines. Annals of the CIRP, 2000, 49(1), 281-284.

4. Neugebauer R., Denkena B., Wegener K. Mechatronic Systems for Machine Tools. Annals of the CIRP, 2007, 56(2), 657-686.

5. Kosinar M., Kuric I. Monitoring of CNC machine tool accuracy Postępy Nauki i Techniki, 2011, 6, 145-154.

6. Skoczyński W. Evaluation of machine tool properties based on machining accuracy of test pieces. Wrocław, Oficyna Wydawnicza PWr, 2001.

7. Piórkowski P., Skoczyński W. Use of the machining programs to determinate the incidence of the machinings operations. Interdyscyplinarność badań naukowych 2016, Wrocław, Oficyna Wydawnicza PWr, 2016, 108-111.

8. ISO 286-2, 2010. Geometrical product specifications (GPS) - ISO code system for tolerances on linear sizes - Part 2. Tables of standard tolerance classes and limit deviations for holes and shafts.

9. Kohlhage E. Über den Zusammenhang zwischen ISA-Toleranz und Oberflächengüte in der spanendem Fertigung. Werkstattstechnik, 1965, 55(5), 230-234.

10. Osanna P.H. Einfluss von Oberflächenrauheit und Formfehlern auf die Werkstückgenauigkeit. Maschinenmarkt, 1980, 86, 281-284.

11. Piórkowski P., Skoczyński W. Statistical Testing of Milled Objects on Numerically Controlled ThreeAxis Milling Machines. Advances in Science and Technology Research Journal. 2021, 15(1), 283-289. 
12. PN-86/M-55552. Obrabiarki do metali- Przedmioty próbne do sprawdzania dokładności - Wymagania ogólne. 1986.

13. PN-M-55667-2, 1994. Warunki odbioru frezarek wspornikowych - Badanie dokładności (withdrawn standard).

14. Ibaraki S., Sawada M., Matsubara A., Matsushita T. Machining tests to identify kinematic errors on five-axis machine tools. Precision Engineering, 2010, 34(3), 387-398
15. Gebhardt M., Knapp W., Wegener K. 5-Axis TestPiece - Influence of Machining Position. The Proceedings of MTTRF 2012 Annual Meeting, 2012, 299-304.

16. Bossoni S. Geometric and Dynamic Evaluation and Optimization of Machining Centers. Dissertation 18383, ETH Zurich, 2010.

17. Wolny R. Evaluation of accuracy of 5-axis CNC milling machine one the basis of test piece machining. Mechanik, 2016, 89(8-9), 1164-1165. 